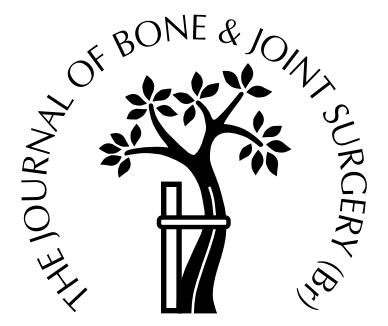

\title{
Early lesions of the labrum and acetabular cartilage in osteonecrosis of the femoral head
}

\author{
P. Kloen, M. Leunig, R. Ganz \\ From the University of Berne, Switzerland
}

O steonecrosis of the femoral head can be caused by a variety of disorders and affects the relatively young patient. Most studies have concentrated on the femoral changes; the sites of early lesions of the labrum and acetabular cartilage have not been recorded. We studied 17 hips with osteonecrosis and a wide congruent joint space on radiographs and by direct inspection of the femoral head, labrum and acetabular cartilage during surgery. All of the femoral heads had some anterosuperior flattening which reduced the head-neck ratio in this area. A consistent pattern of damage to the labrum and the acetabular cartilage was seen in all hips. Intraoperatively, impingement and the cam-effect with its spatial correlation with lesions of the labrum and acetabular cartilage were observed. These findings could be helpful when undertaking conservative surgery for osteonecrosis, since the recognition of early radiologically undetectable acetabular lesions may require modification of the surgical technique.

J Bone Joint Surg [Br] 2002;84-B:66-9.

Received 15 February 2001; Accepted after revision11 July 2001

Many aspects of the aetiology, pathogenesis, natural history and treatment of osteonecrosis of the femoral head remain controversial. $^{1-5}$ It is a disease which affects the relatively young patient. A multitude of aetiological factors has been described including alcohol abuse, corticosteroids, triglycerides, systemic lupus erythematosus (SLE), trauma, infection, dysbarism and the haemoglobinopathies. The underlying lesion is characterised by necrosis of bone with subsequent deformation of the involved part of the femoral head, leading to a stiff painful hip.

P. Kloen, MD, Orthopaedic Surgeon, 1999 M. E. Müller Foundation Fellow Hospital for Special Surgery, 535 East 70th Street, New York, NY 10021, USA.

M. Leunig, MD, Orthopaedic Surgeon

R. Ganz, MD, Professor and Chairman

Department of Orthopaedic Surgery, University of Berne, Inselspital, Berne, 3010-CH, Switzerland.

Correspondence should be sent to Dr M. Leunig.

(C)2002 British Editorial Society of Bone and Joint Surgery 0301-620X/02/112191\$2.00
There are many classifications such as those of Ficat, ${ }^{6}$ Marcus, Enneking and Massam, ${ }^{7}$ Steinberg, Hayken and Steinberg ${ }^{8}$ and the ARCO. ${ }^{9}$ The most commonly used is that of Ficat (Table I) in which the stages range from the silent hip (stage 0) to secondary degeneration (stage IV).

The disease primarily affects the anterosuperior portion of the femoral head, and although progressive deformation will lead to incongruency of the joint with consequent acetabular involvement, it has not been noted as to when and where this initially develops. We have therefore documented the presence and site of early acetabular lesions in a group of patients with osteonecrosis in whom plain radiography still showed a well-preserved joint space and who were thus candidates for conservative surgery, such as revascularisation (stage II) or femoral osteotomy (stage III). $5,7,10-14$

\section{Patients and Methods}

We have studied 17 hips in 14 patients (four women, ten men). Their mean age at the time of surgery was 29 years (14 to 46). They were screened for risk factors for osteonecrosis. The radiological classification was undertaken according to Ficat ${ }^{6}$ (Table I) with anteroposterior (AP) and false-profile and contour views. ${ }^{15}$ Preoperative evaluation included recording the Kerboul angle ${ }^{12}$ which consists of the added arcs of surface involvement on AP and lateral radiographs. The surgical approach was by a Gibson (7 hips) or Kocher-Langenbeck (10 hips) incision with an osteotomy of the greater trochanter. ${ }^{16}$ Anterior subluxation or dislocation was carried out to inspect the joint in the course of conservative surgery and to determine more easily the direction and extent of the intertrochanteric osteotomy (ITO) which would be required in order to

Table I. Classification of osteonecrosis of the femoral head according to Ficat $^{6}$

\begin{tabular}{ll}
\hline Stage & \\
\hline 0 & Preclinical \\
I & Preradiological changes (changes seen only on MRI) \\
II & Diffuse porosis, sclerosis or cysts \\
II to III (transition) & Flattening of femoral head, crescent sign \\
III & Collapse of femoral head \\
IV & Osteoarthritis \\
\hline
\end{tabular}


transfer the load from the affected part of the femoral head. In this approach the tendon of obturator externus is preserved to protect the deep branch of the medial femoral circumflex artery. ${ }^{17}$ We have not observed any increase in the devascularisation of the femoral head. Using a probe the labrum and acetabular cartilage were tested for stability and lesions. The reduced hip was put through a full range of movement under direct view to record the exact relationship between the proximal femur and the acetabulum. This was documented using a graphic representation of the pathological changes. Based on the site of necrosis, inspection of the joint, evaluation of impingement and the extent of the damage, reconstructive surgery was undertaken.

In order to simplify evaluation, all images were converted to represent right-sided joints. The labrum and acetabulum were divided into four quadrants with clockwise marking, 12 o'clock being the most cephalad position. ${ }^{18}$ The lesions of the labrum and acetabulum were assigned numbers correlating with their position. Using computerised data analysis, a frequency distribution was calculated for the site of both the acetabular and labral lesions. The femoral deformity was described in extent and localisation, as well as the cephalocervical offset or ratio.

\section{Results}

The presumed aetiological factors for the development of osteonecrosis in these patients and their details are shown in Table II. The primary complaint in 15 of 17 hips was pain which was related to activity and most often localised in the groin. Sharp pain on flexion, internal rotation and/or adduction of the hip was observed in eight patients (8 hips). The mean duration of symptoms before surgery was 9.3 months (1 to 26). According to the classification of Ficat two hips were stage II, two were stage II to stage III, 12 were stage III, and one was stage III to stage IV. The Kerboul angles were $200^{\circ}$ or more in ten hips (i.e., extensive involvement), between $160^{\circ}$ and $200^{\circ}$ (medium involvement) in four, and in three there were insufficient data since only AP radiographs were available. Plain radiographs showed a well-maintained joint space in all patients.

All hips had a similar pattern of damage to the labrum and acetabular cartilage in the anterosuperior region (Fig. 1). Most often there was a tear of the undersurface of the labrum between 12 and 3 o'clock. An acetabular lesion was seen consistently adjacent to the labral damage. Its appear-

Table II. Details of the 14 patients with osteonecrosis of the femoral head

\begin{tabular}{|c|c|c|c|c|c|c|c|c|c|c|}
\hline Case & $\begin{array}{l}\text { Age } \\
(\text { yrs })\end{array}$ & Gender & Symptoms & Diagnosis & $\begin{array}{l}\text { FICAT } \\
\text { stage }\end{array}$ & $\begin{array}{l}\text { Kerboul angle } \\
\text { (degrees) }\end{array}$ & $\begin{array}{l}\text { Acetabular } \\
\text { cartilage } \\
\text { lesion* }\end{array}$ & $\begin{array}{l}\text { Labral } \\
\text { lesion }\end{array}$ & $\begin{array}{l}\text { Decreased } \\
\text { cephalocervical } \\
\text { offset }\end{array}$ & Treatment \\
\hline 1 & 34 & $\mathrm{~F}$ & Pain & Pregnancy-induced? & III & $\mathrm{NA} \dagger$ & ++ & Tear & + & $\begin{array}{l}\text { Cement augmentation } \\
\text { ITO } \$ \text { (flexion-varus) }\end{array}$ \\
\hline 2 & 17 & M & Pain & After infection & III & 240 & ++ & Tear & + & $\begin{array}{l}\text { Debridement } \\
\text { Labrum and femoral head }\end{array}$ \\
\hline 3 & 18 & M & Pain & Idiopathic & III & NA & + & $\begin{array}{l}\text { Tear } \\
\text { Bony metaplasia }\end{array}$ & + & $\begin{array}{l}\text { Vascularised iliac-crest graft } \\
\text { ITO (flexion-varus) }\end{array}$ \\
\hline 4 & 38 & M & Pain & Hypercholesteraemia & III & 220 & ++ & - & + & $\begin{array}{l}\text { Cement augmentation } \\
\text { Offset improvement }\end{array}$ \\
\hline & 38 & M & No pain & Hypercholesteraemia & II & 260 & + & Degeneration & + & $\begin{array}{l}\text { Cement augmentation } \\
\text { Offset improvement }\end{array}$ \\
\hline 5 & 46 & M & Pain & $\begin{array}{l}\text { Hypercholesteraemia } \\
\text { Alcohol }\end{array}$ & III & 210 & + & Tear & + & $\begin{array}{l}\text { Cement augmentatioin } \\
\text { Offset improvement }\end{array}$ \\
\hline 6 & 32 & M & No pain & Idiopathic & II & 190 & + & Hypertrophy & + & Offset improvement \\
\hline 7 & 14 & M & Pain & Perthes' disease & III & NA & ++ & Tear & + & $\begin{array}{l}\text { Debridement femoral head } \\
\text { ITO (varus) }\end{array}$ \\
\hline 8 & 19 & $\mathrm{~F}$ & Pain & Corticosteroids & III & 235 & ++ & Tear & + & $\begin{array}{l}\text { Drilling femoral head } \\
\text { Offset improvement }\end{array}$ \\
\hline 9 & 38 & M & Pain & Corticosteroids & III & 180 & ++ & Tear & + & $\begin{array}{l}\text { Cement augmentation } \\
\text { ITO (flexion) }\end{array}$ \\
\hline & 38 & M & Pain & Corticosteroids & II to III & 180 & + & Tear & + & $\begin{array}{l}\text { Cement augmentation } \\
\text { ITO (flexion) }\end{array}$ \\
\hline 10 & 25 & $\mathrm{~F}$ & Pain & $\begin{array}{l}\text { SLE } \\
\text { Corticosteroids }\end{array}$ & III & 220 & ++ & Tear & + & ITO (extension-varus) \\
\hline 11 & $\begin{array}{l}34 \\
34\end{array}$ & $\begin{array}{l}\mathrm{M} \\
\mathrm{M}\end{array}$ & $\begin{array}{l}\text { Pain } \\
\text { Pain }\end{array}$ & $\begin{array}{l}\text { Corticosteroids } \\
\text { Corticosteroids }\end{array}$ & $\begin{array}{l}\text { III } \\
\text { III to IV }\end{array}$ & $\begin{array}{l}195 \\
200\end{array}$ & $\begin{array}{l}+ \\
++\end{array}$ & $\begin{array}{l}\text { Tear } \\
\text { Injection }\end{array}$ & $\begin{array}{l}- \\
+\end{array}$ & $\begin{array}{l}\text { Cement augmentation } \\
\text { Cement augmentation } \\
\text { Offset improvement }\end{array}$ \\
\hline 12 & 38 & $\mathrm{~F}$ & Pain & Radiation treatment & II to III & 280 & ++ & $\begin{array}{l}\text { Tear } \\
\text { Bony metaplasia }\end{array}$ & + & Total hip arthroplasty \\
\hline 13 & 17 & M & Pain & $\begin{array}{l}\text { Iatrogenic after } \\
\text { lengthening ITO }\end{array}$ & III & 200 & + & Tear & + & $\begin{array}{l}\text { ITO (extension-varus) } \\
\text { Debridement femoral head }\end{array}$ \\
\hline 14 & 35 & M & Pain & Alcohol & III & 270 & + & Tear & + & $\begin{array}{l}\text { Offset improvement } \\
\text { Drilling femoral head }\end{array}$ \\
\hline \multicolumn{11}{|c|}{$\begin{array}{l}*++ \text {, full thickness; }+ \text {, partial thickness } \\
\dagger \text { not available }\end{array}$} \\
\hline
\end{tabular}




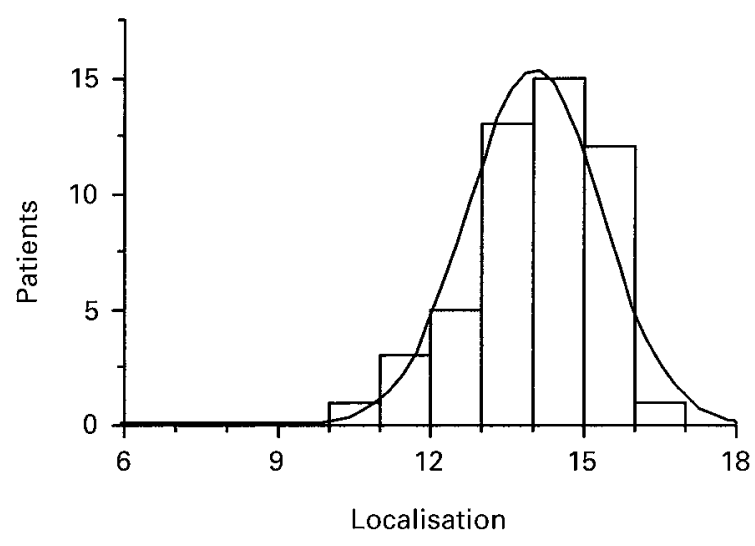

Fig. 1a

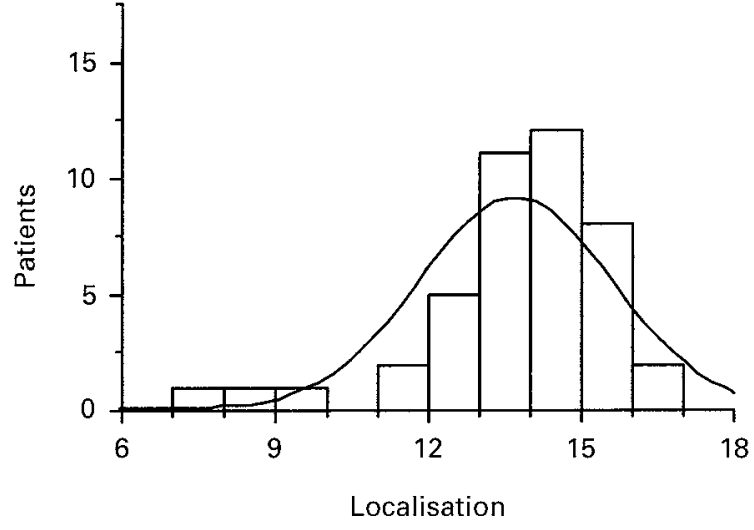

Fig. 1b

Frequency distributions for the site of a) the labral and b) the acetabular lesions.

ance ranged from superficial roughening to an ulcer extending to subchondral bone with adjacent subchondral delamination. The femoral head showed flattening of the contour even in the two hips graded as Ficat stage II. Flattening was more pronounced in advanced stages with more extensive necrosis. Pressure on this region would create a wave-like deformation or buckling at the periphery, thus leaving the outer margins relatively proud. More significant lesions of the acetabulum and labrum were associated with increasing anterosuperior flattening, but this could not be quantified. No correlation could be found between the Kerboul angles and the extent of acetabular and/or labral damage. Intraoperative movement revealed impingement of the anterolateral flattened aspect of the femoral head and/or the femoral head-neck junction against the anterosuperior aspect of the acetabulum and its rim in all hips during flexion and internal rotation and/or adduction. It seemed that prominent edges of cartilage in stage III-hips enlarged the area of acetabular damage. Reconstructive surgery addressing the osteonecrosis and/or impingement included recontouring of the anterior headneck junction (7 hips), cement augmentation of the area of necrosis of the femoral head ${ }^{19}$ (8 hips), ITO (5 flexion, 2 extension), a vascularised graft from the iliac crest (1 hip), arthroplasty (1 hip) and combinations thereof (Table II).

\section{Discussion}

We suggest that the initial damage to the labrum and acetabular cartilage in osteonecrosis of the femoral head is caused by anterior impingement. Deformation of the involved anterosuperior segment of the femoral head leads to a reduced anterior offset between the head and neck, resulting in impingement in flexion and flexion-internal rotation and adduction at the anterosuperior aspect of the labrum and acetabulum. With increasing pressure in flexion, the high stresses between the flattened anterior contour of the femoral head and the opposing surface of the acet- abulum ${ }^{14}$ will lead to lesions on the undersurface of the labrum and destruction at the adjacent acetabular cartilage. Further degeneration results in reactive bony changes as seen in stage IV. We recently reported a similar appearance in patients with a slipped capital femoral epiphysis in whom impingement by the altered contour of the head-neck junction led to early mechanical damage of labral and acetabular cartilage. ${ }^{20}$

The implications of these findings are that, despite an acetabulum which appears radiographically normal (Ficat stages II and III), damage to the labrum and adjacent acetabular cartilage should be anticipated and may warrant conservative surgery. With minor acetabular damage opera-

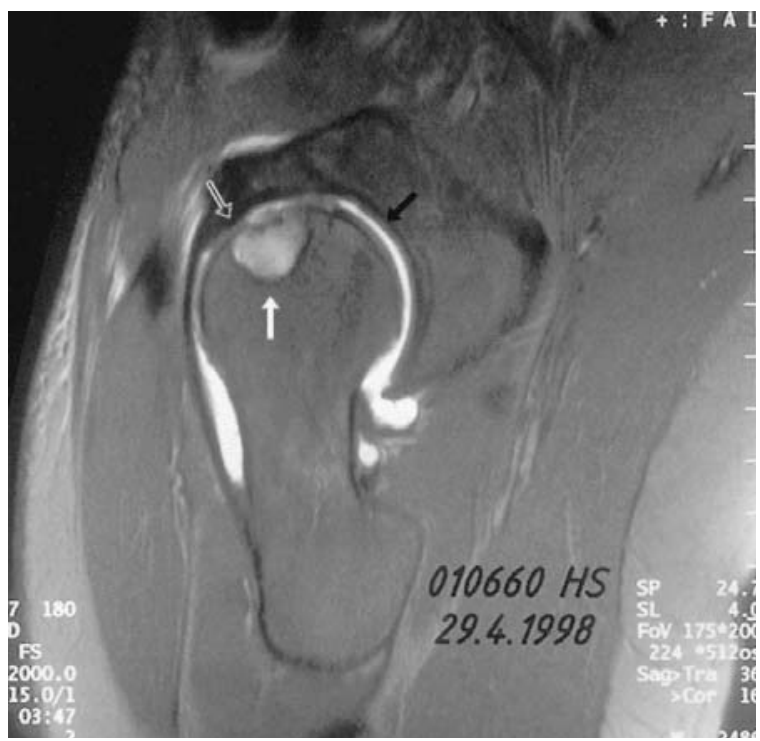

Fig. 2

Case 12. Sagittal oblique plane MRI arthrography (gadolinium) of the hip showing the area of necrosis of the femoral head (closed white arrow). There is discrete subluxation of the femoral head into the defect of the acetabular cartilage at the anterior rim (open white arrow) with consequent widening of the posterior joint space (closed black arrow). 
tion may consist of re-establishment of a sufficient anterior contour of the head by cement, or the head-neck ratio by resection osteoplasty, or an intertrochanteric flexion osteotomy in order to decrease impingement. The accuracy of MRI for assessment of cartilage and labral damage continues to improve ${ }^{18}$ and it is likely that the results of MRI will correlate with the intraoperative findings (Fig. 2). We usually undertake preoperative MRI, but feel that useful additional information can be obtained at the time of surgery using a capsulotomy. Careful preservation of the tendon of obturator externus will prevent further devascularisation. $^{17}$ With high-quality MRI and/or arthroscopy, subluxation of the hip at the time of surgery may not always be necessary. However, it is helpful when checking the direction and extent of the required osteotomy. Arthroscopy of the hip also implies the use of an additional procedure.

Many forms of surgical treatment for osteonecrosis have been described including vascularised bone graft, osteotomy, cement augmentation, core decompression, and arthroplasty. $5,10-14,19,21,22$ Despite increased information about the condition, there are still no clear guidelines as to the appropriate treatment. This is reflected in our patients, who underwent a variety of procedures. We usually recommend a revascularisation procedure in stage-II hips, and cement augmentation with or without osteotomy in stageIII. Drilling of the femoral head is done when the necrotic area is a confluence of irregular zones rather than a clearly defined sector. Recontouring of the anterior head-neck junction is undertaken when there is impingement. ${ }^{20}$ In younger patients, a joint-preserving approach should be pursued, even in the presence of some labral and acetabular pathology. For patients aged over 55 to 60 years it remains unclear as to whether hemiarthroplasty or total hip replacement is the most suitable surgical treatment. Based on our findings, in patients in this age group careful inspection of the joint seems mandatory. When extrapolating from our findings in the younger group we would expect similar or more extensive damage to the labrum and acetabular cartilage which would suggest the requirement of a total hip arthroplasty rather than a hemiarthroplasty. This was also suggested in two recent studies ${ }^{23,24}$ although these authors did not comment on labral pathology or the specific sites of damage to the acetabular cartilage.

We have documented the consistent early presence and sites of labral and acetabular lesions in patients with necrosis of the femoral head who have a radiologically normal joint space without acetabular changes. A mechanical rationale for these lesions is given. The findings may explain why some patients treated by conservative surgery continue to experience pain although the joint space is maintained radiologically. Acetabular damage should be assessed when considering conservative or joint-replacement surgery. Our observations suggest that total hip replacement is more suitable than hemiarthroplasty in these patients.
No benefits in any form have been received or will be received from a commercial party related directly or indirectly to the subject of this article.

\section{References}

1. Aaron RK. Osteonecrosis: etiology, pathophysiology and diagnosis. In: Callaghan JJ, Rosenberg AG, Rubasch HE, eds. The adult hip. Philadelphia, Lippincott-Raven Publishers, 1998:451-66.

2. Hungerford DS. Bone marrow pressure, venography and core decompression in ischemic necrosis of the femoral head. In: The hip: proceedings of the seventh open scientific meeting of The Hip Society. St Louis: CV Mosby, 1979:218-37.

3. Hungerford DS, Zizic TM. Pathogenesis of ischemic necrosis of the femoral head. In: Hungerford DS, ed. The hip. Procs of the 11th meeting of the Hip Society. St. Louis, etc: CV Mosby, 1983:249-62.

4. Mankin HJ. Nontraumatic necrosis of bone (osteonecrosis). $N$ Engl J Med 1991;326:1473-9.

5. Mont MA, Hungerford DS. Non-traumatic avascular necrosis of the femoral head. J Bone Joint Surg [Am] 1995;77-A:459-74.

6. Ficat RP. Idiopathic bone necrosis of the femoral head: early diagnosis and treatment. J Bone Joint Surg [Br] 1985;67-B:3-9.

7. Marcus ND, Enneking WF, Massam RA. The silent hip in idiopathic aseptic necrosis: treatment by bone grafting. J Bone Joint Surg [Am] 1973;55-A:1351-66.

8. Steinberg ME, Hayken GD, Steinberg DR. A quantitative system for staging avascular necrosis. J Bone Joint Surg [Br] 1995;77-B:34-41.

9. ARCO Committee on Terminology and Staging. The ARCO perspective for reaching one uniform staging system of osteonecrosis. In: Schoutens A, ed. Bone circulation and vascularization in normal and pathological conditions. New York, Plenum Press, 1993:375-80.

10. Ito H, Kaneda K, Matsuno T. Osteonecrosis of the femoral head: simple varus intertrochanteric osteotomy. J Bone Joint Surg [Br] 1999;81-B:969-74.

11. Kern O, Klöckner, Weber U. Femur head preserving therapy, using vascular pedicled iliac bone graft, in segmental femoral head necrosis. Orthopade 1998;27:482-90.

12. Kerboul M, Thomine J, Postel M, Merle d'Aubigné R. The conservative surgical treatment of idiopathic aseptic necrosis of the femoral head. J Bone Joint Surg [Br] 1974;56-B:291-6.

13. Saito S, Ohzono K, Ono K. Joint-preserving operations for idiopathic avascular necrosis of the femoral head: results of core decompression, grafting, and osteotomy. J Bone Joint Surg [Br] 1988;70-B:78-84.

14. Wagner H, Baur W, Wagner M. Joint-preserving osteotomy in segmental femur head necrosis. Orthopade 1990;19:208-18.

15. Schneider R. Die intertrochantere Osteotomie bei Coxarthrose. Berlin, etc: Springer Verlag, 1979.

16. Mercati E, Guary A, Myquel C, Bourgeon A. A postero-external approach to the hip joint: value of the formation of a diagnostic muscle. J Chir (Paris) 1972;103:499-504.

17. Gautier E, Ganz K, Krügel N, Gill T, Ganz R. Anatomy of the medial femoral circumflex artery and its surgical implications. J Bone Joint Surg [Br] 2000;82-B:679-83.

18. Leunig M, Werlen S, Ungersböck A, Ito K, Ganz R. Evaluation of the acetabular labrum by MR arthrography. J Bone Joint Surg [Br] 1997;79-B:230-4.

19. Hernigou P, Bachir D, Galacteros F. Avascular necrosis of the femoral head in sickle-cell disease: treatment of collapse by the injection of acrylic cement. J Bone Joint Surg [Br] 1993;75-B:87580 .

20. Leunig M, Casillas MM, Hamlet M, et al. Slipped capital femoral epiphysis: early mechanical damage to the acetabular cartilage by a prominent femoral metaphysis. Acta Orthop Scand 2000;71:370-5.

21. Lachiewicz PF, Desman SM. The bipolar endoprosthesis in avascular necrosis of the femoral head. J Arthroplasty 1988;3:131-8.

22. Urbaniak JR, Harvey EJ. Revascularization of the femoral head in osteonecrosis. J Am Acad Orthop Surg 1998;6:44-54.

23. Steinberg ME, Corces A, Fallon M. Acetabular involvement in osteonecrosis of the femoral head. J Bone Joint Surg [Am] 1999;81-A:60-5.

24. Im G-I, Kim D-Y, Shin J-H, Cho W-H, Lee C-J. Degeneration of the acetabular cartilage in osteonecrosis of the femoral head: histopathologic examination of 15 hips. Acta Orthop Scand 2000;71:28-30. 